\title{
Governing Technology Development: Challenges for Agricultural Research in Africa
}

\section{lan Scoones}

\section{Introduction}

There is little doubt that agricultural research is of critical importance to the future of agriculture in Africa. As an investment, it has been shown again and again to deliver high returns, in terms of both financial benefits (Alston et al. 2000; Evenson and Gollin 2003; although, see Morris and Heisey 2003), and broader livelihood impacts (Meinzen-Dick et al. 2004). Yet agricultural research is in crisis on the continent, its capacity decimated by a combination of government neglect and externally imposed policy conditionalities. This has resulted in a significant loss of key personnel and the undermining of locally based, contextually relevant research efforts. Neither the international system through the CGIAR (Consultative Group on International Agricultural Research), nor the private sector has been able to fill the gap.

In its 2005 report, the Commission for Africa recognises this challenge, and argues for a US $\$ 3 b n$ injection of funds for technology-focused capacity building in Africa. Similarly, the Hunger Taskforce of the Millennium Project argued in 2004 that a science and technology-driven agenda - focused on a green revolution package of seeds, fertilisers and irrigation -was the route to meeting the Millennium Development Goals (MDG) targets. The 2004 InterAcademy Council report also highlighted the challenges of technology development and associated capacity building. Everyone seems to agree that the years of neglect have been disastrous. However, large cash injections and calls for improving "capacity" are one thing; seeing this through to impacts on the ground is another.
This article points to an agenda for social research when thinking about what should be done. In this IDS Bulletin, Jones argues for the need for a new vision for agricultural technology development that can deal with the complexities of agriculture in the diverse settings across Africa. But whose vision should this be? How can complexity and diversity be dealt with? How can innovation systems be made robust, relevant and sustainable? How can the hardware of science and technology be linked to the software of institutions, policy and social dynamics? In sum: how should science and technology be governed?

The following sections offer three themes that should guide this debate. The first relates to how debates are framed and how priorities are set. The second focuses on the actors involved in innovation processes and the locations where innovation takes place. The third emphasises the challenges of organising agricultural research, and the institutional arrangements that govern access and control over knowledge, products and innovation processes. The conclusion highlights the need to inject social and political understandings into new policies for enhancing research and innovation processes in Africa.

\section{Powerful policy framings: challenging priorities in technology research}

Everyone carries with them both explicit and implicit models of the way the world works, or the way the world should be. These "framings" are important when priorities are decided for the allocation of

IDS Bulletin Vol 36 No 2 June 2005 @ Institute of Development Studies 
limited research funds, or when scientists decide on what will be the focus of their experiments. Such perspectives often remain unchallenged, yet they stick with great tenacity. For example, in the field of natural resource management a number of extremely tenacious framings have dominated research and policy thinking since the colonial era. Many are associated with a neo-Malthusian interpretation of the relationships between resources and populations. Thus policy narratives (storylines about cause-effect relationships and suggested intervention solutions; cf Roe 1991) about desertification, soil fertility decline, deforestation and so on have guided both research and intervention. Very often the resulting policies and programmes have been found to be inappropriate, sometimes actually damaging environments and livelihoods. Yet, despite such evidence, the same old views are peddled and the same old policies and interventions promoted (Leach and Mearns 1996).

In the area of agricultural research, a number of framings, promoted and reinforced by powerful global institutions, have become particularly significant. The spectre of a Malthusian crisis is often deployed as a powerful narrative that guides work on global food security, for example. Global, regional or national models highlight deficits of production, pointing towards the need for new investments and technologies to fill the gap (by, e.g. 2015, 2020). The models carry with them an array of often hidden assumptions, but come out with bold conclusions and striking policy messages. Thus the International Food Policy Research Institute, an influential member of the CGIAR system, has produced a series of documents under its 2020 Vision Program, highlighting future food prospects based on a series of models (e.g. Pinstrup-Andersen et al. 1999; von Braun et al. 2005). These documents hold enormous sway in public policy debate internationally, yet (as the authors admit) these models are only models, and in practice there is much more dynamism and diversity on the ground.

Another powerful framing that guides much agricultural policy thinking is the idea that agricultural development occurs through some sort of evolutionary progression or different stages of development. These ideas have a long history (e.g. Johnston and Mellor 1961), and indeed link with much longer traditions of thought defining "progress" and "modernity". Thus Africa is deemed to be at an earlier "stage", requiring certain interventions, but not others. In the area of technology development such evolutionary perspectives, drawing on the highly influential work of Boserup (1981), often define thinking about technology priorities and assumptions about pathways of change. For example, in debates about crop-livestock integration, research efforts have often assumed a pattern of mixed farming as the ideal. This has assumed one technology pathway (from extensive pastoralism, via loosely integrated cropping and livestock systems to a fully integrated, sedentary, private tenure system), dismissing others as backward, inappropriate and not deserving of research investment. Research efforts have systematically ignored an array of crop-livestock permutations and technology options, undermining the potential for productivity and livelihood gains, particularly for poorer, marginal groups and areas (Scoones and Wolmer 2002).

Research on policy processes has revealed how and why such perspectives - in the face of extensive counter-evidence - persist (Fairhead and Leach 2003; Keeley and Scoones 2003). This work highlights how knowledge and policy are constructed together and how certain ideas get embedded in institutional and organisational arrangements, linked to particular people's professional, bureaucratic and sometimes commercial interests.

Challenging mainstream knowledge and policy is therefore not only about garnering new "evidence", but about creating new alliances, networks and political configurations. When ideas are deeply entrenched in bureaucratic structures, educational systems, media representations and political processes, shifting them is an uphill task. This becomes a particular challenge when such framings are linked to powerful global institutions, with large financial clout. Today, when global knowledge networks are increasingly powerful, getting alternative voices heard - particularly those of citizens - is especially challenging (Leach et al. 2005).

Of course science does not emerge independently of the economic, social, and political settings in which it is created. Normative societal values and political imperatives are implicated in the elaboration of scientific questions and technical recommendations, even though these may be "hidden" by their presentation as objective, "technical" issues. Unpacking the origins of and reasons for the persistence of certain narratives is 
an important research agenda that potentially opens up new opportunities for alternative perspectives on seemingly intractable problems.

\section{Actors, locations and networks: reconfiguring innovation processes}

If the broad framings of research and the emerging narratives of problems and solutions are deeply affected by who is involved and their bureaucratic and political setting, then it becomes essential to think critically about participation (in its broadest sense) in agricultural research, both upstream (in terms of defining priorities, questions and framing assumptions) and downstream (in terms of adaptive, applied research, as well as extension and implementation). Two combined processes have been occurring in the agricultural sector globally, with fundamental implications for both the conduct and outcomes of agricultural research. These processes have changed the roles, influences and prominence of actors involved in both science and policy-making, as well as the location of research and development efforts.

The first is the "molecularisation of the life sciences", where upstream, hi-tech solutions to agricultural problems - including biotechnology, and especially transgenics - are seen as the longterm solution. This has resulted in the diversion of public funds to equipping labs and financing new programmes in such areas, often at the expense of field-level efforts. Today, molecular biology is at the top of the prestige hierarchy in agricultural science, with even plant breeding, and certainly field agronomy, way down the pecking order. This has affected perceptions, funding, incentives, career paths and institutional politics, at both national and international levels. This is closely allied to a second trend: the increasing privatisation of public sector agricultural science. Funding levels are not what they used to be and new biotechnology research is expensive, so there is growing reliance on private sector support through contractual, cofinancing and partnership arrangements. This is having a wider impact on what might be termed the "culture of science". Today, high-profile publications, commercial projections, patent applications and start-up companies are seen as central to the scientific enterprise (even in public sector institutions), with old-style "public good" science often getting short shrift (Scoones 2005).
These global trends are helping to reconfigure the actors, locations and networks of research and development (R\&D). With the collapse of research capacity in Africa, this becomes a critical issue. The international agricultural system can only deliver certain things, and these must be adapted, transferred and sometimes fundamentally transformed by local research systems. As Jones (in this IDS Bulletin) notes, the CGIAR system, despite its US $\$ 400 \mathrm{~m}$ annual budget, has not made a huge impact on African rural livelihoods and agricultural productivity over the past few decades. The same applies to the private sector. For all the talk of private sector involvement, public-private partnerships and so on, in the end the private sector will only deliver when it can make a profit. In African rural settings with low population densities, poor infrastructure, weak markets and extensive poverty, this is not easy. It is unsurprising then that, despite the rhetoric, private sector activity in Africa is constrained to a few products (hybrid seeds (including some genetically modified products), fertilisers and some chemicals and drugs) in a few areas (mostly of higher potential).

Yet the main hurdle for agricultural production in Africa is elsewhere - in marginal areas, for labourabsorbing staple food crops and for integrated solutions to the permanent constraints of water, pest and soil fertility management. These are challenges that must be met through painstaking adaptive research, developing contextually relevant, adaptable technologies to particular areas. This requires field-based efforts, interacting with farmers' own contexts and helping design solutions that fit these circumstances. This is of course the now old argument for farmer participatory research (Chambers et al. 1989; Scoones and Thompson 1994). But, except in donor-funded islands, participatory research (and its variants of field-level adaptive and farming systems research) has almost completely ceased in mainstream governmentfunded programmes in Africa.

What therefore should the balance be between upstream, hi-tech generic research and downstream adaptive, context-specific efforts? There are, of course, some examples of generic research efforts which have had wide impact, the iconic case being the dwarf wheat varieties transferred from Mexico to India, which became the spur for the Green Revolution of the 1960s (Byerlee 2000). But these examples are few and far between. Recent surveys 
of successes in African agriculture (e.g. Haggblade and Gebre Mahdin 2004; Mortimore 2005; see also Wiggins, this IDS Bulletin) have shown how technological success is related to context and circumstance, and critically to particular agroecological, institutional, historical and socioeconomic conditions. Overall for Africa, a one-sizefits-all solution is therefore unlikely, making it imperative that a more attuned, locally relevant research agenda is encouraged.

\section{Organising for technology development: challenges for public and private sectors}

Getting such relevant research done has organisational implications. One consequence of the loss of field capacity in national systems in Africa, and the move upstream of other research efforts, is that learning about innovations on the ground is limited. The case of the "system for rice intensification" is instructive. This approach offers the possibility for increasing outputs significantly (although by exactly how much is hotly debated), through a series of management interventions. This system was initially developed in Madagascar and has since spread around the world, with potential for adaptation to other crops. Yet, despite growing evidence and experience, this innovation has largely been shunned by the mainstream research establishment. The field-level, skill-based innovation, which emphasised tillering, not seeds, and management, not genetics, did not appeal. Nor could conventional technology evaluation systems cope with the multi-layered complexity of the innovation, so standard trials foundered (Prasad and Basu 2005).

Complex innovations, involving agro-ecological responses and skill-based management, are often not amenable to conventional research protocols and organisational arrangements. Thus, experiential, field-based learning and adaptive technology design is not seen as legitimate as lab-based experimentation or randomised block designs for well-controlled, station-based trials. The innovators - whether farmers, extension workers or researchers - are not given as much credit, with their results not being written up or accepted by agricultural journals. The organisation of agricultural research is as a result highly selective, often rejecting out of hand findings that might make a wide impact.

Much evidence points to the limits of a linear, top-down, hierarchical model of research, especially when dealing with complex systems (Douthwaite 2002). But, by and large, this has not been taken on board in mainstream agricultural research, whether by CGIAR or national systems. However, increasingly there has been a questioning of how agricultural $\mathrm{R} \& \mathrm{D}$ and innovation systems more broadly are organised (Hall et al. 2001). A few key attributes of effective innovation systems have been highlighted. These include linking research with delivery systems; partnerships between multiple users and researchers; combining supply push with demand pull; developing capacities for participation and learning in innovation systems; and building the institutional infrastructure to make this happen, from local to global levels.

Innovation must be seen as more than just technology research, but as a wider commitment to processes of involving multiple groups of stakeholders in agricultural R\&D. This goes beyond the standard plea for more farmer participation. It recognises the value of farmers' knowledge and understandings in technology design, but also the need to link these inputs into systems of learning and innovation that draw in multiple sources of innovation (cf Biggs 1990), as recognised by the Institutional Learning and Change network of the CGIAR (Mackay and Horton 2003).

Such approaches, based on sharing of technologies and joint innovation partnerships, are all well and good in a well-funded, public sector setting. But as we have seen, this is not the reality on the ground in Africa. These efforts - like farming systems research, "farmer first" approaches and participatory technology development before them - may make little headway without the regeneration of public sector $\mathrm{R} \& \mathrm{D}$, with a renewed commitment to poverty-reducing and livelihoods-enhancing technology research. In an era where private sector $R \& D$ is premised on closed access intellectual property arrangements, commercial confidentiality and a need to recoup large sunken costs, models of learning, participation and partnership can seem rather quaint and old-fashioned. As Mulvany (in this IDS Bulletin) explains, power, ownership and control of the agri-food sector is concentrated increasingly in a few, very large multinational agribusiness corporations. This means that public sector science in terms of available funding, personnel and technology resources, access to patented products and processes and marketing is very much on the sidelines. This is likely to remain 
so, even if the current rhetoric is matched with substantial new investments.

While there are signs that new thinking is beginning to refashion the ways that the currently archaic and ineffective public agricultural systems might work in the future, a significant future challenge will be to think hard about the policy measures and incentives that might influence the governance of private sector $R \& D$ systems. This will have to go beyond rhetorical nods and public relations concessions which have characterised many public-private engagements to date. Instead, measures will need to go to the heart of corporate strategy and financing, if some private sector resources - both intellectual and financial - can be unleashed for the public good in more remote, more marginal areas of Africa. Initiatives such as the African Agricultural Technology Foundation perhaps provide the basis for such new organisational innovations, but the real interests and politics of such arrangements must become more of a focus, interrogating bland assumptions about corporate philanthropy and social responsibility.

\section{Conclusion}

This article has provided a highly schematic assessment of the challenges for agricultural $R \& D$ in Africa. A number of disturbing patterns and trends are evident. Often inappropriate framings of problems and solutions combine with limited field capacity and poorly functioning innovation systems. Inadequate public research and a growing dominance of the private sector - in practice and in culture - means that often there is a narrowing of

\section{References}

Alston, J., Pardey, G., Chan-Kang, T., Wyatt, J. and Marra, M., 2000, 'A meta-analysis of rates of return to agricultural R\&D', Research Report No 113, Washington, D.C.: International Food Policy Research Institute (IFPRI)

Biggs, S., 1990, 'A multiple source of innovation model of agricultural research and technology promotion', World Development, Vol 18 No 11: 1481-99

Boserup, E., 1981, Population and Technology, Oxford: Oxford University Press

Byerlee, D., 2000, 'Efficiency of research investments in the presence of international spillovers: wheat research in developing countries', Agricultural Economics, Vol 22 No 1: 1-16 horizons and scope in research priorities, and potentially a lock-in to particular technological solutions serving particular interests, to the exclusion of others. Technology pathways are increasingly being fashioned by elite science, corporate funding and interests, resulting in a lack of involvement of wider stakeholders. Thus the diverse livelihood pathways and associated agricultural technology demands of poor agriculturalists and pastoralists in Africa are not being served by current arrangements for agricultural innovation.

By narrowing the focus of scientific and technological endeavour, and limiting the possibilities and options available, research systems as currently organised - including the international public system with its global mandate and responsibilities - may act to undermine basic human rights (Richards 2005). This raises fundamental questions about the governance of science and technology for agriculture in Africa: questions of ownership and control; justice and rights; participation and inclusion; and accountability and responsibility. With the current policy debate about agricultural research and technology development so couched in "rational" technical and economic terms, there has been little scope to debate the wider social and political ramifications of new ways of organising, funding and governing agricultural R\&D. An important social and political agenda is suggested for such ongoing initiatives as the International Assessment of Agricultural Science and Technology for Development, one that must be taken into account if the new funding commitments promised are to have any meaningful impact.

Chambers, R., Pacey, A. and Thrupp, L.A., 1989, Farmer First: Farmer Innovation and Agricultural Research, London: Intermediate Technology Publications

Douthwaite, B., 2002, Enabling Innovation. A Practical Guide to Understanding and Fostering Technological Change, London: Zed Books

Evenson, R. and Gollin, D., 2003, Crop Variety Improvement and its Effect on Productivity: The Impact of International Agricultural Research, Wallingford: CAB International

Fairhead, J. and Leach, M., 2003, Science, Society and Power: Environmental knowledge and policy in West Africa and the Caribbean, Cambridge: Cambridge University Press 
Haggblade, S. and Gebre Mahdin, E., 2004, 'Successes in African agriculture: results of an expert survey', World Development, Vol 32 No 5: 745-66

Hall, A., Bockett, G., Taylore, S., Sivamohan, M. and Clark, N., 2001, 'Why research partnerships really matter: innovation theory, institutional arrangements and implications for developing new technology for the poor', World Development, Vol 29 No 5: 783-97

Johnston, B. and Mellor, J., 1961, 'The role of agriculture in economic development', American Economic Review, Vol 51 No 4: 566-93

Keeley, J. and Scoones, I., 2003, Understanding Environmental Policy Processes: Cases from Africa, London: Earthscan

Leach, M. and Mearns, R. (eds), 1996, The Lie of the Land: Challenging Received Wisdom on the African Environment, London: James Currey

Leach, M., Scoones, I. and Wynne, B. (eds), 2005, Science and Citizens. Globalisation and the Challenge of Engagement, London: Zed Books

Mackay, R. and Horton, D. (eds), 2003, 'Institutional learning and change in the CGIAR', Impact Assessment Discussion Paper No 18, Washington, D.C.: IFPRI

Meinzen-Dick, R., Adato, M., Haddad, L. and Hazell, P., 2004, Science and Poverty: an InterDisciplinary Assessment of the Impact Agricultural Research, Washington, D.C.: IFPRI

Morris, M. and Heisey, P., 2003, 'Estimating the benefits of plant breeding research: methodological issues and practical challenges', Agricultural Economics, Vol 29 No 3: 241-52

Mortimore, M., 2005, 'Dryland development: success stories from West Africa', Environment, Vol 46: January-February
Pinstrup-Andersen, P., Pandya Lorch, P. and Rosegrant, W., 1999, World Food Prospects: Critical Issues for the Early Twenty-first Century, Washington, D.C.: IFPRI

Prasad, S. and Basu, K., 2005, 'Understanding scientific controversies: the case of the System of Rice Intensification (SRI)', Paper presented at the 4th IWMI-Tata Annual Partners' Meeting on India's Water Economy: 'Bracing Up for a Turbulent Future', 24-26 February, Anand

Richards, P., 2005, 'Plant biotechnology and the rights of the poor: a technographic approach', in: M. Leach, I. Scoones and B. Wynne (eds), Science and Citizens. Globalisation and the Challenge of Engagement, London: Zed Books: 199-214

Roe, E., 1991, "Development narratives", or making the best of blueprint development', World Development, Vol 19 No 4: 287-300

Scoones, I., 2005, Science, Agriculture and the Politics of Policy. The Case of Biotechnology in India, Hyderabad: Orient Longman

Scoones, I. and Thompson, J. (eds), 1994, Beyond Farmer First: Rural People's Knowledge, Agricultural Research and Extension Practice. London: Intermediate Technology Publications Scoones, I. and Wolmer, W. (eds), 2002, Pathways of Change in Africa: Crops, livestock and livelihoods in Mali, Ethiopia and Zimbabwe, Oxford: James Currey von Braun, J., Rosegrant, M., Pandya-Lorch, R., Cohen, M., Cline, S., Ashby Brown, M. and Soledad Bos, M., 2005, 'New risks and opportunities for food security. Scenario analyses for 2015 and 2050', 2020 Discussion Paper No 39, Washington, D.C.: IFPRI 